\title{
UNIÓN ECONÓMICA Y MONETARIA Y COMUNIDADES AUTÓNOMAS: LA TRANSFORMACIÓN DEL PRINCIPIO DE AUTONOMÍA FINANCIERA
}

\author{
JOAN SOLANES MULLOR \\ Profesor Lector de Derecho Constitucional \\ Universitat Pompeu Fabra
}

TRC, n. ${ }^{\circ} 47,2021$, pp. 383-408

ISSN 1139-5583

\begin{abstract}
SUMARIO
I.Introducción. II. Autonomía financiera y potestad de gasto: la perspectiva constitucional. III. Primera transformación: UEM precrisis. IV. Segunda transformación: UEM en crisis. V. Tercera transformación: la reforma de la UEM y la gestión de los fondos europeos de recuperación. VI. Conclusiones.
\end{abstract}

\section{INTRODUCCIÓN}

El Estado autonómico en España ha estado y continúa estando en permanente revisión. El principio dispositivo marcó, desde el inicio, una gran indeterminación en la concreción y en los detalles de nuestro modelo de organización territorial y ello fue una opción consciente del constituyente que, por tanto, decidió desconstitucionalizar gran parte de la problemática ${ }^{1}$. El modelo de organización territorial quedaba abierto y otras fuentes infraconstitucionales del ordenamiento - llámense Estatutos de Autonomía u otras leyes orgánicas- eran llamadas para su precisión y detalle ${ }^{2}$. Lo que seguramente no previó el constituyente es que el proceso de integración europea, al cual se adheriría España más adelante en 1986, podría ser también un factor de transformación del modelo de pp. 43-48.

1 Fossas Espadaler, E., El principio dispositivo en el Estado autonómico, Marcial Pons-IVAP, 2007,

2 Ibid. pp. 49-56. 
organización territorial. Puede decirse, en pocas palabras, que la influencia de la Unión fue un factor sobrevenido para el constituyente.

La huella de la Unión en el Estado autonómico ha sido analizada ya desde varios ángulos. Por un lado, destacan sobre todo los estudios que analizan las estructuras institucionales a disposición de las CCAA para participar en las políticas de la Unión, ya sea en los procedimientos de decisión de la propia Unión o en los estatales que fijan la posición de España ante ella ${ }^{3}$. Por el otro, existen también aproximaciones doctrinales que analizan ámbitos materiales concretos en los cuales el proceso de integración europea ha sido decisivo en la evolución del Estado autonómico. Destacan, por ejemplo, los estudios sobre la transformación del principio nacional de unidad de mercado, cuyo fortalecimiento tiene mucho que ver con las iniciativas desde la Unión para fortalecer a su vez el mercado interior ${ }^{4}$. O los análisis más recientes, entre los que se incluye este artículo, sobre el impacto de la Unión Económica y Monetaria (UEM) en la autonomía financiera de las CCAA ${ }^{5}$.

En efecto, este artículo pretende mostrar como la autonomía financiera de las CCAA, en su vertiente de potestad o capacidad de gasto, se ha visto transformada a lo largo del desarrollo e implementación de la UEM. La intervención de la Unión ha sido decisiva y no debe subestimarse. El artículo pretende contribuir a explicar las dinámicas relacionales entre constitucionalismo e integración europea y, por tanto, como esta última puede provocar transformaciones constitucionales de gran calado, que, aunque no sean el objetivo de la Unión por ellas mismas, emergen como resultado de sus políticas.

Cabe decir que en la última década el proceso de integración europea se ha visto sometido a un intenso escrutinio desde la óptica del constitucionalismo nacional que ha sido blandido como límite y obstáculo a su avance. Los debates al entorno de la cláusula de identidad constitucional como límite al proceso de integración europea, antes del Tratado de Lisboa formulados bajo la cláusula de respeto a la identidad nacional, han sido recientemente en Europa una constante entre la doctrina ${ }^{6}$. Los fenómenos del Brexit o el choque entre el Tribunal

3 González Pascual, M., Las Comunidades Autónomas en la Unión Europea. Condicionantes, evolución y perspectivas de futuro, Institut d'Estudis Autonòmics, Barcelona, 2013; Muñoz MACHAdO, S. (Dir.), BoIX Palop, A., González Pascual, M., Sarmiento, D., Zelaia Garagarza, M., Las Comunidades Autónomas y la Unión Europea, Academia Europea de Ciencias y Artes, Madrid, 2013.

4 Entre otros, véanse: Albertí Rovira, E., Autonomía Política y unidad económica. Las dimensiones constitucional y europea de la libre circulación y de la unidad de mercado, Civitas, Madrid, 1995; DE LA QUADRA SALCedo Janini, T., Mercado único y Constitución, CEPC, Madrid, 2008; Solanes Mullor, J., «La desconstitucionalización y europeización del principio de unidad de mercado: el Estado de las Autonomías bajo presión», RVAP, n. ${ }^{\circ}$ 109-II, 2017, pp. 89-118.

5 Véase Guerrero VÁzQuez, P., Freno constitucional al endeudamiento y descentralización política. FGA, Zaragoza, 2020; Guerrero VÁzquez, P., «La autonomía financiera de las Comunidades Autónomas en un escenario de consolidación fiscal», Aranda Álvarez, E. (Dir.), Las implicaciones constitucionales de la gobernanza económica europea, Tirant lo blanch, Valencia, 2020.

6 Véase Saiz Arnaiz, A., Alcoberro Llivina, C. (eds.), National Constitutional Identity and European Integration, Intersentia, Cambridge, Amberes y Portland, 2013. 
Constitucional Federal alemán y el Tribunal de Justicia de la Unión Europea (TJUE) en cuanto al programa de compra de deuda pública del Banco Central Europeo ${ }^{7}$ explicitan esta discusión de fondo sobre las líneas rojas o los límites que se erigen desde el constitucionalismo nacional y, al final, sobre la legitimidad última en la que descansa el proyecto europeo.

Los pocos ejemplos que se han traído a colación dan muestra de una relación tormentosa entre constitucionalismo e integración europea, en los que las estructuras constitucionales internas se erigen como diques de contención de una mayor integración o, incluso, abogan o sirven de justificación para su reversión. Todo ello, desde la óptica nacional, descansa en una crítica explícita o implícita a la extralimitación de las competencias de las instituciones de la Unión, ya sea en forma de la adopción de una medida por parte del Banco Central Europeo que no le correspondería conforme a los poderes conferidos en los Tratados o de una doctrina jurisprudencial como es el principio de primacía del Derecho de la Unión que ha ido demasiado lejos en la definición de la relación entre ordenamientos. Las críticas, veladas o no tanto, apuntan al excesivo intervencionismo de la Unión $\mathrm{y}$, hasta cierto punto, su intrusión en esferas propias de los Estados Miembros. A un nivel mucho más discreto, lejos de las grandes discusiones sobre la posible vulneración de la identidad constitucional de un Estado Miembro, se discutía y se continúa discutiendo sobre el papel del principio de autonomía institucional - o procedimental - de los Estados Miembros ${ }^{8}$. Aunque con un alcance mucho más limitado, este principio también ha tenido su espacio en el debate sobre el nivel de intrusión de la Unión en la esfera de decisión propia de los Estados Miembros?.

Este artículo se sitúa lejos de los mencionados debates sobre las fronteras del proceso de integración europea. En todo caso, lo que puede suceder en algunos supuestos, como la influencia del proceso de integración europea en el devenir del Estado autonómico, es que el Derecho de la Unión se aproveche de la textura abierta de las constituciones nacionales ${ }^{10}$. La Constitución española de 1978 no se aparta de este rasgo distintivo del constitucionalismo y permite que el Derecho de la Unión permee e induzca transformaciones ${ }^{11}$. En España, precisamente, la

7 BVerfG, judgment of the Second Senate of 5 May 2020 - 2 BvR 859/15, paras. 1-237 (ECLI:DE:BVerfG:2020:rs20200505.2bvr085915) y posterior comunicado de prensa del TJUE n. ${ }^{\circ}$ 58/20, de 8/05/2020.

8 SChwarze, J., «El Derecho administrativo europeo a la luz del Tratado de Lisboa: observaciones preliminares», Fuertes López, M. (coord.), Un procedimiento administrativo para Europa. Cizur Menor, Aranzadi, 2012, p. 48.; Arzoz, X., «La autonomía institucional y procedimental de los Estados Miembros en la Unión Europea: Mito y realidad», RAP, n. ${ }^{\circ} 191,2013$, pp. 163-165.

9 Kakouris, C.M., «Do the Member States possess judicial procedural 'autonomy'?», Common Market Law Review, n. ${ }^{\circ}$ 34(6), 1997, p. 1408; Delicostopoulus, J., «Towards European Procedural Primacy in National Legal Systems», European Law Journal, n. ${ }^{\circ}$ 9(5), 2003, pp. 599-560.

10 Guastini, R., Teoría e ideología de la interpretación constitucional, Trotta, Madrid, 2008, p. 30.

11 Sobre la flexibilidad interpretativa de la Constitución española, véase Ferreres Comella, V., The Constitution of Spain. A Contextual Analysis, Hart Publishing, Oxford y Portland, 2013. 
organización territorial del Estado se configura como uno de los principios constitucionales más abiertos de nuestro ordenamiento constitucional o, mejor dicho, más indeterminados ${ }^{12}$. Así, delante de esta característica del ordenamiento constitucional español, el Derecho de la Unión encuentra oportunidades para inducir cambios en el modelo de organización territorial en el caso de que sus objetivos y políticas lo hagan necesario. La necesidad de instaurar un régimen de disciplina de gasto común en el seno de la UEM ha comportado, como se verá, que en España se reduzca la autonomía financiera de las CCAA y que se haya optado por un control férreo de las finanzas públicas desde las instituciones centrales.

Precisamente, para calibrar adecuadamente el grado de intervención de la Unión, es necesario en primer lugar analizar cómo se configuraba, en términos constitucionales iniciales, la autonomía financiera de las CCAA (apartado II). A continuación, se analiza la evolución e implementación de la UEM y se identifican tres etapas distintas en las que se desgrana su influencia en la autonomía financiera de las CCAA. Una primera etapa en la que la UEM es poco invasiva (UEM precrisis, apartado III), una segunda en la que se produce una influencia intensa (UEM en crisis, apartado IV) y finalmente la etapa actual que persiste en la intrusión (la reforma de la UEM y la gestión de los fondos europeos de recuperación, apartado V). Para acabar, se esbozan unas breves conclusiones que enfatizan la estrecha relación entre constitucionalismo, el proceso de integración europea y el devenir del Estado autonómico.

\section{AUTONOMÍA FINANCIERA Y POTESTAD DE GASTO: LA PERSPECTIVA CONSTITUCIONAL}

Pese a la indeterminación aludida y a la voluntad consciente del constituyente de optar por su desconstitucionalización, es indudable que el modelo de organización territorial se erige como una decisión y contenido de primera importancia en la Constitución española de 1978 (CE). El debate sobre qué modelo adoptar y cómo resolver uno de los contenciosos históricos en el haber del Estado español fue parte del proceso de negociación política de la transición española a la democracia y formó parte del denominado «consenso» constitucional que dio a luz al nuevo ordenamiento constitucional ${ }^{13}$. Precisamente, el principio dispositivo y la desconstitucionalización como elementos estructurales del Título VIII de la Constitución reflejan la dificultad del acuerdo político en una materia históricamente difícil de solucionar y dejaban abierto, para una concreción posterior, el modelo de organización territorial ${ }^{14}$. La remisión a completar el modelo a

12 Ariño Ortiz, G., «Las autonomías, tres cuestiones cardinales», Cuenta y razón, n. ${ }^{\circ}$ 3, 1981, pp. 29-32.

13 Ferreres Comella, V., op. cit., pp. 162-166.

14 Fossas Espadaler, E., op. cit., pp. 44-48. 
través de normas infraconstitucionales —en especial los Estatutos de Autonomía- buscaba hacer partícipes a los territorios que deseaban acceder a la autonomía y, también, instaurar una cierta asimetría de base en el modelo ${ }^{15}$.

Desconstitucionalización, sin embargo, no significa que el constituyente no tomase ninguna decisión sobre el modelo de organización territorial. Lejos de ello, el constituyente sí que se pronunció sobre los elementos estructurales del modelo y, por tanto, los principios de la organización territorial del Estado sí que fueron constitucionalizados ${ }^{16}$. Los principios de «unidad», «autonomía política» y «solidaridad», reconocidos en el artículo $2 \mathrm{CE}$, son los valores constitucionales que vertebran todo el modelo y que guían todo el despliegue de sus detalles mediante la normativa infraconstitucional ${ }^{17}$. Sin duda alguna, la Constitución se convierte en una guía para el desarrollo del modelo de organización territorial español, pero son sobre todo los Estatutos de Autonomía los encargados del detalle.

En todo caso, la garantía de la autonomía política de las CCAA es seguramente el rasgo más distintivo de la arquitectura constitucional y ha sido definida y concretada por el Tribunal Constitucional en una ya consolidada jurisprudencia desde los años ochenta. En efecto, si bien la Constitución solamente menciona el «derecho a la autonomía», sin más calificativos, el Tribunal Constitucional la ha caracterizado como autonomía política, no meramente administrativa, y ello comporta asumir facultades legislativas y gubernativas ${ }^{18}$. En definitiva, las CCAA gozan de discrecionalidad, sobre todo entendida como capacidad legislativa, para decidir sus propias políticas siempre dentro del marco de distribución de competencias fijado por la Constitución y los respectivos Estatutos de Autonomía. Como puede deducirse, los principios de unidad y solidaridad ejercen el papel de límites al principio de autonomía política y configuran las fronteras del libre ejercicio de las competencias propias de las CCAA $^{19}$.

Es aquí, como parte instrumental para la autonomía política garantizada, que entra en juego la autonomía financiera. El artículo 156.1 CE garantiza dicha autonomía a las CCAA "para el desarrollo y ejecución de sus competencias con arreglo a los principios de coordinación con la Hacienda estatal y de solidaridad entre todos los españoles». Más allá de sus límites, la Constitución solamente anuncia la garantía de la autonomía financiera y le otorga este carácter instrumental, es decir, la califica como necesaria para el ejercicio competencial — poner en práctica la autonomía política- de las CCAA. No encontramos ninguna definición a nivel constitucional y, de nuevo, ha sido el Tribunal Constitucional el encargado de elaborar el concepto de autonomía financiera. Dejando de lado la

15 Ferreres Comella, V., op. cit., pp. 185-190.

16 Fossas Espadaler, E., op. cit., pp. 81-88.

17 Ferreres Comella, V., op. cit., pp. 166-169.

18 STC 25/1981, par. 3; STC 4/1981, par. 3.

19 Respecto al principio de unidad como límite a la autonomía política, véase la STC 4/1981, par. 3. Respecto a la solidaridad como límite, véase la STC 64/1990, par. 7. 
dimensión de la suficiencia de ingresos — autonomía financiera entendida como la capacidad de recaudar e ingresar recursos suficientes para ejercer políticas propias-, nos interesa más, por la afectación de la UEM, la otra cara de la moneda: la autonomía financiera como capacidad de gasto, es decir, la potestad de decisión sobre el gasto para poder ejercer políticas propias.

En efecto, entendida en este sentido, la autonomía financiera se vislumbra como clave para poder hacer efectiva la autonomía política. En esta dimensión, engloba la capacidad para elaborar y ejecutar un presupuesto propio (autonomía presupuestaria) y estructurar el nivel de gasto, en definitiva, llevar a cabo una política presupuestaria propia ${ }^{20}$. Tener la llave del gasto, es decir, poder decidir qué gastar y cómo distribuirlo, está íntimamente relacionado con la capacidad de poder llevar a la práctica políticas propias ${ }^{21}$.

Esta relevancia constitucional de la autonomía financiera en su dimensión de potestad de gasto poco nos dice sobre los concretos límites a los que se encuentra sometida. Es un valor constitucional central en el modelo de organización territorial, pero poco más podemos deducir del texto constitucional. El Tribunal Constitucional ha precisado que del artículo 156.1 CE emana una facultad de coordinación del poder central que limita, por tanto, el alcance de la autonomía financiera de las $\mathrm{CCAA}^{22}$. Esta facultad de coordinación debe completarse con títulos competenciales específicos a favor del nivel central, especialmente la competencia para establecer las bases y coordinar la planificación general de la actividad económica reconocida en el artículo 149.1.13 CE, que le permiten permear la autonomía financiera de las CCAA.

Pese a estos límites, el Tribunal Constitucional también ha aclarado que la autonomía política, y por ende la financiera como instrumento de aquella, tiene un mínimo irreductible que en ningún caso puede sobrepasarse. Por un lado, la facultad de coordinación que emana del artículo 156.1 CE no significa jerarquía, en ese sentido, coordinación y jerarquía no son equiparables ${ }^{23}$. Se ha descartado, por tanto, un posible poder general de supervisión por parte de las instituciones centrales $^{24}$. Por otro lado, siempre debe respetarse un mínimo de discreción a las CCAA dentro de su propio ámbito de competencias y esto significa que en ningún caso pueden ser sustituidas en el ejercicio de sus competencias ${ }^{25}$. Esto ha sido recalcado, específicamente, en el ámbito de la autonomía financiera y por tanto cobra una gran relevancia en el ámbito de la potestad de gasto ${ }^{26}$.

20 STC 63/1986, par. 9; STC 13/1992, par. 7.

21 STC 13/1992, par. 7. Véase LóPEz PÉREz, A., La hacienda autónoma: una propuesta alternativa para la Comunidad Valenciana, Bosch, Barcelona, 2009, pp. 55-57.

22 STC 11/1984, par. 5; STC 63/1986, par. 8; STC 62/2001, par. 4

23 STC 76/1983, par. 12; STC 27/1987, par. 6; STC 40/1998, par. 53.

24 Medina Guerrero, M., «La constitucionalización del principio de estabilidad presupuestaria», Revista de Estudios Regionales, n. ${ }^{\circ} 105,2016$, p. 85.

25 STC 201/1988, par. 4; STC 13/1992 par. 7.

26 STC 171/1996, par. 3. 
En definitiva, la autonomía financiera de las CCAA, ya sea considerada de manera autónoma o como parte de la autonomía política, se configura como un principio constitucional del modelo de organización territorial del Estado. Goza, por tanto, de protección constitucional, pero sin que se pueda deducir del propio texto de la Constitución de 1978 el alcance de esta. El Tribunal Constitucional ha intentado detallar este alcance, pero solamente ha dado, igual que el texto constitucional, guías para la resolución de conflictos, como son entender que la coordinación no es jerarquía o que en todo caso se debe respetar un mínimo de discrecionalidad y no sustituir a las CCAA en el ejercicio de sus competencias. Se trata, por tanto, de criterios jurisprudenciales abiertos, aplicables caso a caso, que no solucionan de raíz la indeterminación textual constitucional.

Así, la indeterminación del constituyente y la no excesiva concreción por parte del Tribunal Constitucional dificultan que, en términos de los grandes debates europeos, pueda concluirse que el modelo de organización territorial previsto en la Constitución de 1978 forma parte de la identidad constitucional de España. Parece bastante claro que el Estado autonómico es una decisión constitucional y en sus valores centrales está protegido, pero el constituyente optó por un elevado grado de indeterminación y por una fuerte desconstitucionalización que hace que el Estado autonómico esté al albur de las normas infraconstitucionales. En este sentido, el Tribunal Constitucional, en su formulación de la doctrina de los contra-límites respecto al principio de primacía del Derecho de la Unión, en ningún momento mencionó de manera expresa el modelo de organización territorial español como línea roja que no pueda traspasarse ${ }^{27}$.

La indeterminación textual en esta materia, unida a la poca concreción del Tribunal Constitucional, hacen que el Estado autonómico presente poca batalla al proceso de integración europea. Mejor dicho, en el avance del proyecto de integración europea no aparece el Estado autonómico como una barrera sólida en el caso de que el Estado decida, en aras de satisfacer objetivos y políticas de la Unión, limitar la capacidad de actuación de las CCAA. En otras palabras, las barreras constitucionales que protegen el Estado autonómico, aunque existen, no son muy resistentes a embates del poder central que puedan venir alentados por las instituciones de la Unión.

Esta protección débil de las costuras del Estado autonómico podría verse compensada con una participación adecuada de las CCAA en el seno de la Unión o en los procesos de toma de decisiones del Estado ante la Unión. Si bien las políticas de la Unión o las del poder central pueden afectar a la autonomía financiera de las CCAA, la falta de barreras constitucionales de protección podría verse corregida por una participación robusta de aquellas en la formulación de esas

27 Véase la Declaración del Tribunal Constitucional 1/2004, par. 2. En una formulación ambigua, el Tribunal Constitucional expresó que se debe respetar «la soberanía del Estado, nuestras estructuras constitucionales básicas y el sistema de valores y principios fundamentales consagrados en nuestra Constitución, en el que los derechos fundamentales adquieren sustantividad propia». 
políticas. Deviene por eso crucial, y lo haremos en las siguientes líneas, estudiar qué capacidad de intervención en esas políticas han tenido y tienen las CCAA.

\section{PRIMERA TRANSFORMACIÓN: UEM PRECRISIS}

La UEM cobra cuerpo por primera vez en la década de los noventa con el camino hacia la moneda única. En efecto, la necesidad de armonizar las políticas económicas y fiscales de los Estados Miembros que perseguían la integración en la zona Euro se vio ineludible a efectos de dar sustento a la moneda única ${ }^{28}$. En este contexto, la disciplina fiscal de los Estados Miembros — también desde la perspectiva de la capacidad de gasto- - fue centro de atención desde las primeras formulaciones de la $\mathrm{UEM}^{29}$. El control del gasto público y la garantía del principio de estabilidad presupuestaria se erigieron como criterios de convergencia para entrar en la zona Euro y por primera vez la Unión se dotó de un mecanismo para controlar el déficit excesivo de los Estados Miembros ${ }^{30}$.

La adopción de la moneda única, por tanto, comportó el establecimiento de límites sustantivos a la capacidad de gasto de los Estados Miembros impuestos desde la Unión. El Tratado de Maastricht de 1992 y el Pacto de Estabilidad y Crecimiento (Stability and Growth Pact, SGP) en su primera formulación de la década de los noventa introdujeron la necesidad de coordinación de las políticas económicas de los Estados Miembros ${ }^{31}$, prohibieron el déficit excesivo como principio general ${ }^{32} \mathrm{y}$ finalmente establecieron el tope máximo para incurrir en déficit presupuestario sin que se considerase «excesivo» ${ }^{33}$. Sin embargo, aunque se previó un mecanismo de control para supervisar a los Estados Miembros en el cumplimiento de la disciplina de gasto ${ }^{34}$, este se puso en pocas ocasiones en práctica

28 Carrera Hernández, F.J., «El Six-Pack y el Two-Pack ¿Más allá de las competencias atribuidas en los Tratados?», Aranda Álvarez, E. (Dir.), Las implicaciones constitucionales de la gobernanza económica europea, Tirant lo Blanch, Valencia, 2020, pp. 35-42.

29 Ruiz Tarrías, S., Las dimensiones constitucionales de la Unión Económica y Monetaria Europea, Civitas, Pamplona, 2016, pp. 39-67.

30 Los criterios de convergencia se fijaron por primera vez en el antiguo art. $109 \mathrm{~J}$ del Tratado de la Comunidad Europea (TCE, en su redacción dada por el Tratado de Maastricht) y fueron desarrollados por el Protocolo n. ${ }^{\circ} 13$ sobre criterios de convergencia.

31 Art. 103 TCE, en su redacción dada por el Tratado de Maastricht. La coordinación económica se pretendía más intensa a través de un mecanismo de supervisión periódico que descansaba en la obligación de presentar los «programas de estabilidad». Véase el Reglamento (CE) n. ${ }^{\circ}$ 1466/97 del Consejo, de 7/07/1997, relativo al reforzamiento de la supervisión de las situaciones presupuestarias y a la supervisión y coordinación de las políticas económicas.

32 Art. 104c TCE, en su redacción dada por el Tratado de Maastricht.

33 Protocolo n. ${ }^{\circ} 12$, sobre el procedimiento aplicable en caso de déficit excesivo. Los límites quedaron fijados en el $3 \%$ del déficit público y el $60 \%$ de deuda pública, valores en proporción al producto interior bruto de cada país.

34 El mecanismo de supervisión inicial se anclaba en el antiguo art. 104c TCE, en su redacción dada por el Tratado de Maastricht y en el art. 3 del Protocolo n. ${ }^{\circ} 12$. Fue desarrollado en mayor detalle en el 
y se toleraron de facto incumplimientos del régimen fiscal común, como fueron los casos de Alemania y Francia ${ }^{35}$. La reforma del SGP en 2005 no varió esta primera formulación, comportó introducir los denominados objetivos presupuestarios a medio plazo para una más estrecha supervisión de las políticas presupuestarias de los Estados Miembros ${ }^{36}$, y, asimismo, una flexibilización del procedimiento de déficit excesivo que permitía a la Comisión y al Consejo ser más transigentes a la hora de analizar un posible incumplimiento de los Estados Miembros ${ }^{37}$.

La implementación de esta primera formulación de la UEM en España se llevó a cabo a nivel infraconstitucional. Se impuso el principio de estabilidad presupuestaria a nivel central a través del artículo 3 de la Ley 18/2001, de 12 de diciembre, General de Estabilidad Presupuestaria y a nivel de las CCAA y entes locales en el artículo 3 de la Ley Orgánica 5/2001, de 13 de diciembre, complementaria a la Ley General de Estabilidad Presupuestaria. Más allá de la introducción de este principio limitador en el momento de elaborar y aprobar todo presupuesto, se reservó al Estado la determinación del déficit público en el que podían incurrir las CCAA $^{38}$. La reforma española de 2006, en consonancia con la reforma de 2005 del SGP, introdujo las mismas variables de flexibilización fijadas a nivel europeo ${ }^{39}$. En síntesis, la UEM, que exigía el control del gasto de los Estados Miembros que persiguieran la adopción de la moneda única, cristalizó en España en un entramado legislativo, de carácter infraconstitucional, que consa-

Reglamento (CE) n. ${ }^{\circ}$ 1467/97 del Consejo, de 7/07, relativo a la aceleración y clarificación del procedimiento de déficit excesivo. En síntesis, los Estados Miembros estaban obligados a proporcionar su situación presupuestaria a la Comisión. En caso de que la Comisión entendiera que el Estado pudiera estar incurriendo en déficit excesivo, tenía que dirigirse al Consejo, que por mayoría cualificada decidía si se incurría en tal déficit. El Consejo, seguidamente, podía emitir recomendaciones al Estado Miembro en cuestión, primero con carácter confidencial y, si no se atendían, podían hacerse públicas. En caso de persistir el incumplimiento, el Consejo podría decidir aplicar sanciones.

35 En estos dos casos, el Consejo de la Unión llegó a declarar que se incurría en déficit excesivo (Decisión 2003/89/CE en el caso de Alemania y Decisión 2003/487/CE en el caso de Francia). Pese a ello, y en contradicción con las propuestas de la Comisión, el Consejo decidió suspender en sus conclusiones el procedimiento de déficit excesivo en el Consejo de la Unión celebrado el 25/11/2003. El Tribunal de Justicia anuló las conclusiones del Consejo, pero no se desprendió ningún efecto sancionador o práctico para los dos países (STJUE C-27/04, de 13/07/2004, Comisión/Consejo, EU:C:2004:436).

36 Véase el Reglamento (CE) n. ${ }^{\circ} 1055 / 2005$ del Consejo, de 27/06, por el que se modifica el Reglamento (CE) n. ${ }^{\circ}$ 1466/97 del Consejo relativo al refuerzo de la supervisión de las situaciones presupuestarias y a la supervisión y coordinación de las políticas económicas.

37 Véase el Reglamento (CE) n. ${ }^{\circ}$ 1056/2005 del Consejo, de 27/06, por el que se modifica el Reglamento (CE) n. ${ }^{\circ} 1467 / 97$ relativo a la aceleración y clarificación del procedimiento de déficit excesivo.

38 Art. 5 y 6 L.O. 5/2001. En el caso español, se dejó en manos del Gobierno central la determinación del déficit nominal de las CCAA, a diferencia de otros sistemas descentralizados, como por el ejemplo el alemán, que centran el control sobre el déficit estructural de los entes subestatales. Controlar el déficit nominal, es decir, el déficit anual de cada ejercicio presupuestario y no el estructural a largo plazo, supone una mayor injerencia en la autonomía financiera de los entes subestatales. Véase a este respecto Guerrero VÁzQuEZ, P., «La autonomía financiera de las Comunidades Autónomas en un escenario de consolidación fiscal», op. cit., p. 332 .

39 Modificaciones introducidas por la Ley $15 / 2006$ y L.O. 3/2006. 
gró el principio de estabilidad presupuestaria y centralizó la determinación del déficit público de todas las administraciones públicas.

La autonomía financiera de las CCAA, en su vertiente de capacidad de gasto, quedaba aminorada por estos límites sustantivos a su política presupuestaria, especialmente por la fijación del déficit público en el que podían incurrir. Esta limitación podría haber sido amortiguada si las CCAA hubiesen gozado de un nivel de participación aceptable en la toma de decisión de la fijación y reparto del déficit público, es decir, si allá dónde se fijaban los límites, ya sea en la Unión o a nivel estatal, hubiesen poseído voz y voto. En cuanto a la capacidad de participación de las CCAA en la toma de decisiones de la UEM, aquí no se apreció ninguna diferencia respecto a las dificultades que siempre han encontrado las regiones europeas para participar en la Unión Europea ${ }^{40}$. En efecto, las regiones tienen pocos canales de participación en las instituciones de la Unión y, menos aún, en el entramado de la UEM, en cuyo diseño siempre han sido protagonistas la Comisión y el Consejo ${ }^{41}$.

Esta situación tampoco mejoró en los procedimientos estatales previstos para fijar la posición de España ante la Unión Europea. Hasta 2004, el sistema de participación de las CCAA en los asuntos europeos se basó en las conferencias sectoriales, en el seno de las cuales eran informadas de las políticas europeas, se discutían las mismas y se llegaban a acuerdos con el Gobierno central ${ }^{42}$. El sistema de conferencias sectoriales se complementaba con la participación de las CCAA en los comités de la Comisión y también con la posibilidad, aunque con muchas limitaciones, de poder litigar ante el Tribunal de Justicia de la Unión Europea $^{43}$. Todo ello bajo la coordinación central y con una clara primacía de las instituciones centrales, hecho que ha comportado una fuerte crítica al modelo español por sus deficiencias en cuanto a facilitar la efectiva participación de las CCAA en los asuntos europeos ${ }^{44}$. La reforma del sistema de participación en 2004 supuso una mejora decisiva, puesto que permitió la participación directa de las

40 Pérez Tremps, P., Comunidades Autónomas, Estado y Comunidad Europea, Ministerio de Justicia, Madrid, 1987, pp. 131-132; Martín Pérez De NanClares, J., «Comunidades Autónomas y Unión Europea: hacia una mejora de la participación directa de las Comunidades Autónomas en el proceso decisorio comunitario», Revista de Derecho Comunitario Europeo, n. ${ }^{\circ} 22,2005$, p. 763.

41 Los canales de participación en la UE de las regiones han sido la posible participación directa en el Consejo desde el Tratado de Maastricht, aunque dicha participación dependa de la voluntad del Estado, el sistema de consultas ante la Comisión cuando exista un interés regional (Dialogue with associations of regional and local authorities on the formulation of European Union Policy, $\operatorname{COM}(2003) 811$ final), la creación del Comité de las Regiones (CDR), regulado actualmente en los arts. 305 y ss del Tratado de Funcionamiento de la Unión Europea (TFUE), y el acceso al Tribunal de Justicia de la Unión Europea, especialmente por parte del CDR en uso del recurso de anulación previsto en el art. 263, inciso tercero, TFUE. Véase al respecto MuÑOz MACHAdo, S. (Dir.), op. cit., 173-176.

42 Acuerdo sobre Participación Interna de las CCAA en los Asuntos Comunitarios a través de Conferencias Sectoriales de 30/11/1994.

43 González Pascual, M., op. cit., pp. 54-74.

44 Ibid. pp. 125-128. 
CCAA en el Consejo y en los órganos de preparación de las reuniones del Consejo, en especial el COREPER ${ }^{45}$. Sin embargo, dicha participación directa se circunscribe a concretas formaciones del Consejo, sin alcanzar la formación económica o monetaria, que es la relevante para la $\mathrm{UEM}^{46}$. En definitiva, ni directamente ante la Unión ni a través de los mecanismos de participación internos en los asuntos europeos, las CCAA participaron en el proceso de toma de decisiones de la UEM.

Ahora bien, a pesar de esta deficiencia en la participación directa a nivel de la Unión, la implementación inicial de la UEM en España dejó un margen aceptable de participación interna a las CCAA en cuanto al reparto del déficit público $^{47}$. Si bien el Gobierno central era preponderante en la decisión, se canalizaba la participación de las CCAA a través del Consejo de Política Fiscal y Financiera (órgano de colaboración multilateral). En efecto, el Consejo emitía informe previo a la determinación por parte del Gobierno central del déficit total para el conjunto de las CCAA y, a continuación, le correspondía también al Consejo la determinación individualizada del déficit para cada Comunidad Autónoma ${ }^{48}$. La reforma de 2006 incluso fomentó la participación a nivel bilateral entre Gobierno central y CCAA en la determinación individualizada del déficit ${ }^{49}$. Además de esta participación en la toma de decisiones a nivel interno, el marco normativo español del momento no preveía un sistema de control robusto que sujetara a las CCAA. El desvío de los límites de déficit fijados comportaba la obligación de la Comunidad Autónoma de presentar un «plan económico-financiero de reequilibrio» al Consejo de Política Fiscal y Financiera, pero nada más, sin que fuera posible la aplicación de sanciones ${ }^{50}$.

Cabe resaltar la similitud entre el diseño de la primera UEM y la implementación que se llevó a cabo en España en esta primera etapa. Tanto a nivel de la Unión como del Estado, se fijaron límites sustantivos a la capacidad de gasto, si se quiere ver así, desde la Unión hacia los Estados Miembros y en España, desde el centro hacia los entes subestatales. En ambos casos, sin embargo, la capacidad de control y supervisión se vio limitada puesto que los mecanismos previstos fueron débiles, básicamente se articularon instrumentos de suministro de información, elaboración de planes de corrección y emisión de recomendaciones. Mucho tiene

45 Acuerdos de 9/12/2004, de la Conferencia para Asuntos Relacionados con las CCEE, sobre la Consejería para Asuntos Autonómicos en la Representación Permanente de España ante la UE y sobre la participación de las CCAA en los grupos de trabajo del Consejo de la UE; y sobre el sistema de representación autonómica en las formaciones del Consejo de la UE.

46 A lo largo del tiempo se ha ido ampliando la posibilidad de participar en diferentes formaciones del Consejo, pero no se ha llegado a incluir la formación económica. Véase GonZÁlEz PASCUAL, M., op. cit., pp. 77-79.

47 Guerrero VÁzQuez, P., «La autonomía financiera de las Comunidades Autónomas en un escenario de consolidación fiscal», op. cit., pp. 336-337.

48 Art. 6 L.O. 5/2001, en su redacción original.

49 Art. 5.3 L.O. 5/2001, en su redacción dada por la L.O. 3/2006. Véase Bellod Redondo, J.F., «Déficit y ciclo económico en la reforma de la ley de estabilidad presupuestaria», Auditoría Pública, n. ${ }^{\circ} 43$, 2007, pp. 96-97.

50 Arts. 7 y 8 L.O. 5/2001. 
que ver esta falta de previsión de un marco sancionador en caso de incumplimiento de las exigencias de la UEM con el hecho de que nos encontramos en un momento dulce de la integración europea, es decir, la UEM estaba inmersa en la construcción de la moneda única y lejos de una situación de crisis ${ }^{51}$. Especialmente desde la Unión Europea no se centró la atención en el incumplimiento estatal y, mucho menos, se señalizó o culpabilizó a los entes subestatales por incurrir en déficit excesivo. Este clima positivo en ese momento de la integración europea propició una menor intrusión de la Unión en las decisiones internas de los Estados Miembros.

En este sentido, el sistema constitucional español se moduló sin grandes sobresaltos. La primera implementación de la UEM se realizó a nivel infraconstitucional, sin necesidad de acudir a una reforma constitucional. Si bien se produjo una limitación efectiva de la autonomía financiera de las CCAA — con la adopción del principio de estabilidad presupuestaria y la centralización de la determinación del déficit público-, su participación a nivel estatal en el reparto del déficit y la falta de mecanismos sancionadores minoraron el impacto. El Tribunal Constitucional, que tuvo oportunidad de pronunciarse sobre algunas dimensiones de esta primera implementación, asumió con naturalidad la modulación de la autonomía financiera de las $\mathrm{CCAA}^{52}$.

\section{SEGUNDA TRANSFORMACIÓN: UEM EN CRISIS}

La crisis financiera de 2008 cambió el contexto positivo en Europa y las dificultades en el proceso de integración europea florecieron ${ }^{53}$. La UEM no fue una excepción y se acometió una reforma en profundidad de su diseño ${ }^{54}$. Mejor dicho, los principios estructurales de la UEM no cambiaron, es decir, la disciplina de gasto impuesta a los Estados Miembros bajo el principio de estabilidad presupuestaria y el control del déficit y deuda pública se mantuvieron inalterados ${ }^{55}$. Lo que se afrontó

51 Carrera Hernández, F.J., op. cit., p. 41.

52 STC 134/2011.

53 Chiti, E., Gustavo Teixeira, P., «The Constitutional implications of the European responses to the financial and public debt crisis», Common Market Law Review, n. ${ }^{\circ}$ 50(3), 2013, pp. 683-685.

54 Calvo Hornero, A., «La arquitectura económica y financiera de la UEM y los efectos de la crisis», Cuadernos Europeos de Deusto, n. ${ }^{\circ}$ 49, 2013, pp. 92-93.

55 El Tratado de Estabilidad, Coordinación y Gobernanza en la Unión Económica y Monetaria (TECG), pese a ser un acuerdo intergubernamental fuera del Derecho de la Unión, mantuvo los mismos principios que los Tratados de la Unión y el Protocolo n. ${ }^{\circ}$ 12. Se endureció, eso sí, el control del déficit excesivo con la introducción de una nueva regla que fijaba el límite máximo admisible de déficit estructural en el $0.5 \%$ (salvo que la deuda pública fuera inferior al 60\%, en ese caso el límite de déficit estructural se elevaba al 1\%), véase el artículo 3.1 b) y d) TECG. Por tanto, si bien se mantenían los valores máximos del 3\% de déficit público nominal y el $60 \%$ de deuda pública fijados por el Protocolo n. ${ }^{\circ} 12$, se puso el foco en un mayor control del déficit estructural. Precisamente, el mandato de incorporar el principio de estabilidad presupuestaria a nivel interno establecido en el art. 3.2 TECG, "preferentemente de rango constitucional», ejemplificó de 
fue una transformación a fondo del mecanismo de supervisión y control existente en la UEM hasta entonces que se centró en mejorar su efectividad ${ }^{56}$.

Un breve repaso de la reforma de la UEM durante la crisis de 2008 nos muestra esta voluntad de la Unión de centrarse en la mejora de los mecanismos de control. El denominado Six Pack, un paquete de medidas de reforma del SGP lanzado en 2011, avanzó en esta línea. El Semestre Europeo agudizó la supervisión y seguimiento de la disciplina fiscal de los Estados Miembros, esto a través de la obligación de elaborar los Programas Nacionales de Reforma (PNR) y los Programas de Estabilidad (PE), que después posibilitaban la emisión de recomendaciones específicas a los Estados Miembros ${ }^{57}$. Se reforzó el Procedimiento de Déficit Excesivo (PDE) con la introducción de un régimen sancionador y en general se dotó de mayor disciplina al SGP ${ }^{58}$. Se crearon dos nuevos mecanismos de control que, en el caso de iniciarse respecto a un Estado Miembro, acarrean nuevas obligaciones de suministrar información. Por un lado, el Procedimiento de Desequilibrios Macroeconómicos (PDM), que permite al Consejo emitir recomendaciones de carácter orientativo al Estado Miembro ${ }^{59}$. Por el otro, el Procedimiento de Desequilibrios Excesivos (PDI), en el cual las recomendaciones del Consejo adquieren un valor más allá del meramente orientativo ${ }^{60}$. Finalmente se quiso uniformar la metodología presupuestaria y evitar discrepancias en la manera de elaborar las cuentas públicas ${ }^{61}$.

El denominado Two Pack, lanzado en 2013, acabó de robustecer el mecanismo de supervisión de la disciplina de gasto de los Estados Miembros. Destaca, sobre todo, la obligación de presentar el proyecto de presupuestos generales a la Comisión, que se suma a la necesidad introducida en 2005 de presentar los Programas de Estabilidad y los Planes Fiscales Nacionales a Medio Plazo (MTOs) ${ }^{62}$. Asimismo, en caso de que un Estado Miembro esté sujeto a un PDI o a un Programa de Asistencia Financiera, se encontrará bajo la denominada «supervisión reforzada» que le comportará un control más estrecho por parte de las instituciones

nuevo el compromiso con los principios de disciplina fiscal mantenidos hasta el momento por la Unión, pero la necesidad de dar pasos adelante en su efectiva implementación a nivel interno de los Estados Miembros. Por otro lado, el Tratado Constitutivo del Mecanismo Europeo de Estabilidad (MEDE), también como acuerdo intergubernamental, profundizó en la coordinación económica de los Estados Miembros, con la creación del MEDE y, de nuevo, afianzó principios estructurales ya existentes en la UEM.

56 Ruffert, M., «The European debt crisis and European Union Law», Common Market Law Review, n. ${ }^{\circ} 48(6), 2011$, pp. 1794-1797.

57 Véase el Reglamento (UE) n. ${ }^{\circ} 1175 / 2011$ del Parlamento Europeo y del Consejo, de 16/11/2011.

58 Véanse el Reglamento (UE) n. ${ }^{\circ} 1177 / 2011$ del Consejo, de 8/11/2011 y el Reglamento (UE) n. ${ }^{\circ} 1173 / 2011$, del Parlamento Europeo y del Consejo, de 16/11/2011.

59 Art. 6.1 Reglamento (UE) n. ${ }^{\circ} 1176 / 2011$ del Parlamento Europeo y del Consejo, de 16/11/2011 (recomendaciones del Consejo sobre la base del art. 121.2 TFUE).

60 Art. 7.2 Reglamento (UE) n. ${ }^{\circ} 1176 / 2011$ (recomendaciones del Consejo sobre la base del art. 121.4 TFUE). Véase también el Reglamento (UE) n. ${ }^{\circ}$ 1174/2011 del Parlamento Europeo y del Consejo, de 16/11/2011.

61 Véase la Directiva 2011/95/EU del Parlamento Europeo y del Consejo, de 13/12/2011.

62 Reglamento (UE) n. ${ }^{\circ}$ 473/2013 del Parlamento Europeo y del Consejo, de 21/05/2013. 
europeas $^{63}$. En definitiva, tanto el Six Pack como el Two Pack aumentaron las obligaciones de suministrar información de los Estados Miembros en cuanto a la disciplina de gasto y, en algunos casos, sobre todo en el supuesto de estar sujeto al PDI, las recomendaciones del Consejo adquieren un matiz más cercano a la vinculación, dejando de lado la «suavidad» anterior del mecanismo de control de la UEM.

La recepción de la reforma de la UEM en España comportó una afectación mucho más intensa al principio de autonomía financiera de las CCAA que en la época precrisis. Si bien la UEM no varió la esencia de sus principios estructurales, España sí que decidió imponer mayores limitaciones sustantivas a la capacidad de gasto de las CCAA y apostó por una mayor centralización del gasto ${ }^{64}$. Estas limitaciones no provinieron tanto de la reforma constitucional del artículo $135 \mathrm{CE}$, puesto que la ahora cláusula constitucional de estabilidad presupuestaria es de nuevo de textura abierta ${ }^{65}$, sino más bien de la normativa infraconstitucional que se aprobó en desarrollo de aquella. La Ley Orgánica 2/2012, de 27 de abril, de Estabilidad Presupuestaria y Sostenibilidad Financiera (LOESP) continuó apostando por dejar en manos del Estado la fijación del déficit público, se agudizó el control de la deuda pública autonómica con el principio de sostenibilidad financiera, se introdujo una agresiva regla del gasto y se limitó la denominada deuda comercial $^{66}$. Fuera de estos principios limitadores establecidos en la legislación de estabilidad presupuestaria, la articulación de fondos condicionados a favor de las CCAA — los denominados Fondos de Liquidez Autonómica, FLA — también ha provocado una merma en la capacidad de decisión sobre el gasto de aquellas ${ }^{67}$.

A estas limitaciones sustantivas se le suma un mecanismo de supervisión, control y sanción en caso de no cumplir con la disciplina de gasto que se encuentra alineado con la voluntad de la UEM de ser más vigilante, en este caso respecto a las $\mathrm{CCAA}^{68}$. En primer lugar, en su vertiente preventiva, se somete a supervisión a las $\mathrm{CCAA}^{69}$. En segundo lugar, en caso de producirse supuestos de incumplimientos, se permite al Estado tomar medidas correctivas ${ }^{70}$. En tercer y último

63 Reglamento (UE) n. ${ }^{\circ} 472 / 2013$ del Parlamento Europeo y del Consejo, de 21/05/2013.

64 Medina Guerrero, M., «La constitucionalización de la regla del equilibrio presupuestario: integración europea, centralización estatal», REP , n. ${ }^{\circ} 165,2014$, pp. 196-208.

65 Medina Guerrero, M., «El Estado autonómico en tiempos de disciplina fiscal», $R E D C$, n. $^{\circ} 98$, 2013, pp. 119-120.

66 Guerrero Vázquez, P., «La autonomía financiera de las Comunidades Autónomas en un escenario de consolidación fiscal», op. cit., pp. 335-352.

67 Medina Guerrero, M., «La constitucionalización de la regla del equilibrio presupuestario: integración europea, centralización estatal», op. cit., pp. 198-204.

68 Medina Guerrero, M., «El Estado autonómico en tiempos de disciplina fiscal», op. cit., pp. 135144; Guerrero VÁzquez, P., «La autonomía financiera de las Comunidades Autónomas en un escenario de consolidación fiscal», op. cit., pp. 352-356.

69 Arts. 18 y 19 LOESP.

70 Arts. 20 a 24 LOESP. Entre ellas, se puede someter a autorización estatal todas las operaciones de endeudamiento de la Comunidad Autónoma, sus subvenciones o suscripción de convenios. También se puede exigir la formulación de planes económico-financieros y planes de reequilibrio. 
lugar, y seguramente aquí se encuentra la mayor novedad y también afectación a la autonomía financiera de las CCAA, en caso de persistir el incumplimiento se entra en la fase coercitiva, en la que se pueden imponer sanciones e, incluso como última opción, recurrir al artículo $155 \mathrm{CE}^{71}$.

Todo ello no viene acompañado de una mayor participación de las CCAA en los procesos de decisión en el seno de la UEM o a nivel estatal. En efecto, los mecanismos de supervisión endurecidos a nivel de la Unión se articulan como foros de comunicación y diálogo entre las instituciones de la Unión —en especial la Comisión y el Consejo-y los Estados, sin que las regiones tengan protagonismo. Todas las obligaciones de suministro de información que sirven de base a las recomendaciones emanadas de la Comisión y del Consejo son elaboradas y propuestas por el Estado. Este último decide internamente quien es el interlocutor en el seno del mecanismo de supervisión de la UEM, en el caso español, el Gobierno central. En definitiva, la UEM en época de crisis ha sido diseñada para controlar la disciplina del gasto público de los Estados Miembros, sin que la organización territorial interna del Estado sea una variable preponderante.

Esto no supone una novedad respecto a las viejas estructuras de la UEM, pero lo que sí que cambia en esta segunda etapa es la capacidad de participación de las CCAA a nivel interno en las medidas de disciplina del gasto. Por un lado, la participación de las CCAA en la determinación de la posición de España ante la Unión no ha cambiado, continua sujeta a las viejas y deficientes estructuras ya descritas. Por el otro, la normativa de estabilidad presupuestaria ha rebajado notablemente el nivel de participación de las CCAA. En efecto, el papel anterior del Consejo de Política Fiscal y Financiera se reduce y, mucho más, la bilateralidad introducida en 2006 en la fijación del déficit público. Las instituciones centrales toman el protagonismo en la toma de decisiones y se relega a la Comunidad Autónoma a un papel consultivo ${ }^{72}$. Es interesante recalcar el nuevo protagonismo de la Autoridad Independiente de Responsabilidad Fiscal (AIREF), puesto que asume la emisión de informe previo a la decisión del Gobierno central en el reparto individualizado del déficit de cada Comunidad Autónoma ${ }^{73}$. Y ello cuando la AIREF es un ente que se articula como una autoridad administrativa

71 Arts. 25 y 26 LOESP. Entre ellas, se puede impedir la disponibilidad de créditos y retenciones, asumir las competencias normativas en materia de tributos cedidos o exigir un depósito del 0,2\% del PIB regional.

72 El establecimiento del objetivo de estabilidad presupuestaria anual (nivel de déficit) para el conjunto de administraciones públicas lo fija el Gobierno de manera unilateral mediante acuerdo del Consejo de Ministros (art. 15.1 LOESP). El establecimiento del déficit individualizado para cada Comunidad Autónoma lo vuelve a fijar el Gobierno mediante otro acuerdo del Consejo de Ministros (art. 16 LOESP). Las Comunidades Autónomas solamente participan en la toma de la decisión en el seno del Consejo de Política Fiscal y Financiera, que en ambos casos solamente se prevé que emita informe previo a la decisión del Gobierno.

73 Art. 16 LOESP. 
independiente de ámbito estatal y es ajena a los intereses o representación de las CCAA $^{74}$.

Este endurecimiento hacia las CCAA no es ajeno a la presión ejercida, de manera directa, por parte del mecanismo de supervisión europeo de la UEM. En efecto, en 2009 se inició un Procedimiento de Déficit Excesivo (PDE) contra España, que se prolongó hasta $2019^{75}$, mientras que en 2012 España fue sometida a un Procedimiento de Desequilibrios Macroeconómicos (PDM $)^{76}$. No cabe olvidar que España también solicitó un Programa de Asistencia Financiera, de carácter condicionado, y que por tanto fue sometida también a un Memorando de Entendimiento $(\mathrm{MoU})^{77}$. Estos dos procesos de supervisión bajo la estructura de la UEM y la sujeción al MoU han puesto el foco en el incumplimiento de España respecto a la disciplina fiscal y la necesidad de revertir la situación. Lo que nos interesa en este momento es constatar que en el diálogo que se ha producido bajo estos mecanismos de supervisión entre las instituciones europeas y España se ha enfatizado el papel, como agente incumplidor, de las CCAA. Y esto ha sido tanto desde la Unión en la formulación de sus recomendaciones como desde el Estado en la suministración de información bajo el mecanismo de control de la UEM.

Así, bajo la supervisión ordinaria del Semestre Europeo, se ha producido una intensa comunicación entre las instituciones de la Unión y España. En el suministro de información de España a la Unión a través de los Programas de Estabilidad (PE) y los Programas Nacionales de Reforma (PNR), ha sido una constante por parte del Gobierno español señalar a las CCAA como mayores responsables del déficit público y la necesidad de controlarlas de $\operatorname{cerca}^{78}$. Las reacciones de la

74 La AIREF se concibe como institución estatal. Su presidente es nombrado por el Consejo de Ministros, previa comparecencia en el Congreso de los Diputados (art. 24 L.O. 6/2013). No se articula en su interior ningún comité u órgano con presencia de representantes de las Comunidades Autónomas.

75 Decisión del Consejo 2009/417/CE de 27/04/2009; Decisión (UE) 2019/1001 del Consejo, de 14/06.

76 En 2012, la Comisión, en el primer Informe sobre el mecanismo de Alerta (IMA) que elaboró desde la creación del PDM, señaló la necesidad de realizar un examen exhaustivo a España (COM/2012/068 final). Desde entonces y hasta el día de hoy, la Comisión ha calificado a España con desequilibrios graves (en 2013 y 2014, véanse COM/2012/0751 final y COM/2013/0790 final) o solamente con desequilibrios (del 2015 hasta el día de hoy, véase el último Informe sobre el mecanismo de Alerta de 2020, COM/2019/651 final), hecho que ha comportado que se someta a España desde 2012 a sucesivos Exámenes Exhaustivos.

77 Memorándum de Entendimiento sobre condiciones de Política Sectorial Financiera, hecho en Bruselas y Madrid el 23/07/2012, y Acuerdo Marco de Asistencia Financiera, hecho en Madrid y Luxemburgo el 24/07/2012.

78 Respecto a los PNR, véase PNR 2011, p. 40; PNR 2012, p. 59-60; PNR 2013, p. 97; PNR 2014, p. 98; PNR 2015, p. 95; PNR 2016, p. IV; PNR 2017, p.17; PNR 2018, pp.27-28, p. 71; PNR 2019, p. 15. Pueden consultarse todos los PNR presentados por España ante las instituciones europeas en Portal Institucional del Ministerio de Hacienda [consulta: 22/12/2020]. Disponible en: https:/www.hacienda.gob.es/es-ES/ CDI/Paginas/EstrategiaPoliticaFiscal/ProgramaNacionalReformas.aspx.

Respecto a los PE, véase PE 2011, p. 5; PE 2012, p. 7; PE 2013, p. 22, PE 2014, p. 53; PE 2015, p. 20; PE 2016, p. 62; PE 2017, p. 52; PE 2018, p. 54; PE 2019, p. 65. Pueden consultarse todos los PE presentados por España ante las instituciones europeas en Portal Institucional del Ministerio de Hacienda [consulta: 22/12/2020]. Disponible en: https://www.hacienda.gob.es/es-ES/CDI/Paginas/EstrategiaPoliticaFiscal/Programasdeestabilidad.aspx. 
Comisión y el Consejo a través de las recomendaciones específicas a España después de analizar los PE y PNR han sido positivas, en el sentido de entender adecuada la tarea del Gobierno español en reducir el déficit a nivel regional, pero también han expresado una clara preocupación al entender que son las CCAA las principales causantes del déficit excesivo y que resulta necesario aplicar estrictamente la normativa española de estabilidad presupuestaria ${ }^{79}$.

En cuanto al Procedimiento de Déficit Excesivo (PDE) abierto contra España en 2009, después de un periodo sin mencionar a las CCAA, a partir de 2012 se aprecia que tanto la Comisión como el Consejo las señalaron como causantes del déficit excesivo de España ${ }^{80}$. Las instituciones de la Unión recogieron este sentir expresado por el Gobierno español y constataron deficiencias en la aplicación de la normativa española de estabilidad presupuestaria ${ }^{81}$. Destacó, sobre todo, el diálogo mantenido entre las instituciones de la Unión y España en 2016, con la casi imposición de una multa por déficit excesivo a España. Aquí, tanto la Comisión como el Consejo pusieron el foco en las CCAA como principales responsables del gasto y la necesidad de aplicar de manera efectiva la normativa española de estabilidad presupuestaria ${ }^{82}$.

Bajo el Procedimiento de Desequilibrios Macroeconómicos (PDM) se produjo un diálogo similar. En los Informes sobre el mecanismo de Alerta (IMA), momento en el que se define y califica la situación de desequilibrio del Estado Miembro, no se señaló en ningún momento directamente a las CCAA ${ }^{83}$. En los Exámenes Exhaustivos $^{84}$, sin embargo, sí que se expresó que el incumplimiento de las CCAA en

79 Véanse la Recomendación del Consejo de 12/07/ 2011 (2011/C 212/01), considerando 8 y recomendación 1; Recomendación del Consejo de 10/07/2012 (2012/C 219/24), considerando 10 y recomendación 1; Recomendación del Consejo de 9/07/2013/ (2013/C 217/20), considerando 10 y recomendación 1; Recomendación del Consejo de 8/07/2014 (2014/ C 247/08), recomendación 1; Recomendación del Consejo de 14/07/2015 (2015/C 272/13), considerando 9 y recomendación 1; Recomendación del Consejo de 12/07/2016 (2016/C 299/02), considerando 5.

80 Pueden consultarse toda la documentación del PDE relativo a España en Comisión Europea [consulta: 22/12/2020]. Disponible en: https://ec.europa.eu/info/business-economy-euro/economic-and-fiscal-policy-coordination/eu-economic-governance-monitoring-prevention-correction/stability-and-growth-pact/ corrective-arm-excessive-deficit-procedure/closed-excessive-deficit-procedures/spain_en.

81 Recomendación de la Comisión para la adopción de una Recomendación del Consejo, de 6/07/2012 $\operatorname{COM}$ (2012) 0397 final, considerando 9; Recomendación del Consejo de 21/06/, encaminada a poner fin a la situación de déficit público excesivo de España, 2013/C 180/02, considerando 14.

82 Recomendación de la Comisión de 9/12/2016, relativa a las medidas que debe adoptar España para garantizar una corrección oportuna de su déficit efectivo C(2016) 5200 final, considerandos 4, 6 y 10; Decisión (UE) 2016/1222 del Consejo de 12/07/2016, por la que se establece que España no ha tomado medidas eficaces para seguir la Recomendación de 21/06/2013 del Consejo, considerando 11; Decisión de ejecución (UE) 2017/2351 del Consejo de 9/08/2016 sobre imposición de una multa a España por no haber adoptado medidas efectivas para corregir su déficit excesivo, considerando 13.

83 Pueden consultarse todos los IMA en Comisión Europea [consulta: 22/12/2020]. Disponible en: https:/ ec.europa.eu/info/business-economy-euro/economic-and-fiscal-policy-coordination/eu-economic-governance-monitoring-prevention-correction/macroeconomic-imbalances-procedure/alert-mechanism-report_en.

84 Pueden consultarse todos los Exámenes Exhaustivos relativos a España en Comisión Europea [consulta:22/12/2020].Disponibleen:https://ec.europa.eu/info/business-economy-euro/economic-and-fiscal-policycoordination/eu-economic-governance-monitoring-prevention-correction/macroeconomic-imbalances-procedure/depth-reviews_en. 
cuanto al principio de estabilidad presupuestaria comportaba un riesgo global para la situación económica del país ${ }^{85}$. Se hicieron también apelaciones a la necesidad de aplicar de manera efectiva la normativa de estabilidad presupuestaria y en algunos casos se denunció que no se habían llegado a aplicar medidas correctivas o coercitivas en casos de incumplimiento ${ }^{86}$. Se denunció, por tanto, que el uso limitado de las medidas previstas en la normativa española de estabilidad presupuestaria no generaba incentivos adecuados para garantizar la disciplina fiscal a nivel de las CCAA ${ }^{87}$.

Finalmente, el MoU firmado por España y la Comisión para acceder a un Programa de Asistencia Financiera enfatizó la obligación de España de corregir la situación de déficit excesivo antes de 2014. Además de la obligación de presentar un presupuesto plurianual para 2013-2014 que especificase las medidas estructurales necesarias para corregir el déficit excesivo, el MoU hizo un llamamiento expreso a aplicar «sin fisuras» la Ley de Estabilidad Presupuestaria ${ }^{88}$. Claramente se recogió de nuevo el sentir que las instituciones europeas habían dejado claro en el PDE, el PDM y la supervisión ejercida bajo el Semestre Europeo, es decir, que era necesario para España atajar el déficit excesivo y que este traía causa, principalmente, en el gasto desmesurado de las CCAA.

En definitiva, esta segunda etapa de transformación constitucional que conllevó una reducción de la autonomía financiera de las CCAA se produjo bajo una intensa influencia de los mecanismos de supervisión de la UEM que pusieron el foco en las CCAA. En el diálogo entre las instituciones de la Unión y el Gobierno español bajo las estructuras de supervisión de la UEM, las CCAA quedaron estigmatizadas y se las señaló repetidamente como causantes del déficit excesivo de España e, incluso, como factor de desequilibrio macroeconómico. El endurecimiento interno del régimen de control de la disciplina de gasto de las CCAA coincidió con este diálogo en el seno de la UEM.

De nuevo aquí los principios constitucionales del modelo de organización territorial no se erigieron en barreras fuertes al proceso de integración europea y, así, la supervisión dentro de las estructuras de la UEM durante el periodo de la crisis financiera de 2008 influyó de manera directa, con apelaciones concretas al modelo territorial, en su transformación. El Tribunal Constitucional, al igual que en la primera oleada, asumió con naturalidad la modulación constitucional y validó íntegramente la normativa infraconstitucional de estabilidad presupuestaria que reformuló la autonomía financiera de las CCAA $^{89}$.

85 Comisión Europea, «Macroeconomic imbalances. Spain», Occasional Papers, n. ${ }^{\circ} 103,2012$, p. 42.

86 Comisión Europea, «Macroeconomic imbalances. Spain», Occasional Papers, n. ${ }^{\circ}$ 216, 2015, pp. 2 y 46; Comisión Europea, Country Report Spain 2016, SWD(2016) 78 final, pp. 70, 78 y 80-81.

87 Comisión Europea, Country Report Spain 2017, SWD(2017) 74 final, pp. 3, 25-30; Comisión Europea, Country Report Spain 2018, SWD(2018) 207 final, p.28.

$88 \mathrm{MoU}$, apartados 29 a 31.

89 Véase, la STC 215/2014, Mediante este pronunciamiento el TC analiza la constitucionalidad de prácticamente toda la LOESP, tanto las limitaciones sustantivas a la autonomía financiera como el marco de supervisión y control (medidas preventivas, correctivas y coercitivas) previsto por aquella, sin que 


\section{TERCERA TRANSFORMACIÓN: LA REFORMA DE LA UEM Y LA GESTIÓN DE LOS FONDOS EUROPEOS DE RECUPERACIÓN}

La reforma de la UEM que se ha planteado recientemente no supone ningún cambio en cuanto a la poca participación de las regiones en el proceso de integración europea ${ }^{90}$. Todas las iniciativas planteadas han sido paralizadas por la crisis de la Covid-19 y la dificultad de consenso para su aprobación entre los Estados Miembros, pero resulta interesante detenerse en ellas, aunque sea someramente, para constatar que no se produce ninguna alteración sustancial en una UEM diseñada por y para los Estados, sin que el factor regional sea relevante. Asimismo, la pandemia, pese a no afectar a las estructuras de la UEM tal y como están articuladas hoy en día, ha traído como novedad la articulación de una gran cantidad de fondos europeos que se ponen a disposición de los Estados Miembros para hacer frente a las necesidades de la crisis sanitaria y económica $^{91}$. Se hará también una referencia sintética a su gestión y al papel de las CCAA en ellos.

La primera propuesta de reforma de la UEM alude a la creación del Fondo Monetario Europeo (FME), que desea remplazar al MEDE e integrar esta estructura en el Derecho de la Unión ${ }^{92}$. Al igual que el MEDE, el FME que se propone no incorpora a las regiones europeas en sus mecanismos de decisión ${ }^{93}$. Como mucho, los parlamentos regionales pueden asumir una función residual de control a través del principio de subsidiariedad, puesto que el FME será responsable frente a las instituciones de la Unión y también ante los parlamentos nacionales ${ }^{94}$. Asimismo, la propuesta de creación del denominado Ministro de Economía y Finanzas se articula como una iniciativa de redistribución de responsabilidades entre Comisión, Consejo y Eurogrupo, sin que las regiones tengan ningún papel ${ }^{95}$. Tampoco la propuesta sobre «nuevos instrumentos presupuestarios» facilita un

encuentre ninguna tacha de inconstitucionalidad. Se ha producido alguna resolución posterior del Tribunal Constitucional que también ha analizado algún aspecto concreto del régimen de la LOESP, como por ejemplo la STC 101/2016, en relación con los límites a la deuda comercial, sin encontrar tampoco tachas de inconstitucionalidad.

90 Para una panorámica de las reformas planteadas hasta el día de hoy, véase OLESTI RAYO, A., «The institutional consolidation of the Economic and Monetary Union within the European Union: proposals and actions», Revista Catalana de Dret Públic, n. ${ }^{\circ}$ 59, 2019, pp. 36-41.

91 Para más detalles sobre el «Plan de recuperación para Europa», consúltese Comisión Europea [consulta: 22/12/2020]. Disponible en: https://ec.europa.eu/info/strategy/recovery-plan-europe_en.

92 Propuesta de Reglamento del Consejo relativo a la creación del Fondo Monetario Europeo, de 6/12/2017, COM(2017) 927 final.

93 Tanto el Consejo de Gobernadores como el Consejo de Directores se componen de integrantes nombrados por los Estados Miembros. La Comisión y el Banco Central Europeo también tienen representantes, pero sin derecho a voto. Véanse los arts. 5 y 6 de la propuesta de Estatuto del FME.

94 Art. 6 propuesta de Reglamento relativo a la creación del FME, de 6/12/2017, COM(2017) 927 final.

95 Comunicación de la Comisión al Parlamento Europeo, al Consejo Europeo, al Consejo y al Banco Central Europeo: un Ministro Europeo de Economía y Finanzas, de 6/12/2017, COM(2017) 823 final. 
espacio a las regiones, puesto que trata de un conjunto de nuevas herramientas dentro del ámbito del derecho presupuestario de la Unión ${ }^{96}$.

Más relevantes a nuestro efecto son las propuestas relacionadas con el paquete de medidas para fortalecer la responsabilidad fiscal y la orientación presupuestaria a medio plazo en los Estados Miembros ${ }^{97}$. Esta propuesta tiene como objeto principal interiorizar dentro de la Unión el entramado intergubernamental del TECG $^{98}$. Seguramente, una de sus claves institucionales más importantes es el reforzamiento del papel de los organismos nacionales independientes encargados de velar por la disciplina fiscal ${ }^{99}$. Así es, la propuesta pretende robustecer este tipo de organismos, tanto su estatus de independencia frente a las instituciones políticas de los Estados Miembros, como su papel dentro del mecanismo de supervisión de la disciplina fiscal. La propuesta de la Unión solamente exige un nivel mínimo de configuración institucional de estos organismos y cabría la posibilidad de incorporar a las regiones europeas, a nivel de cada organismo estatal, en su seno ${ }^{100}$. Al verse directamente afectadas por las medidas de disciplina fiscal, parece acertado hacerlas partícipes, o por lo menos abrirles canales de participación dentro de las estructuras institucionales de estos organismos. Hasta el momento, la AIREF se encuentra ajena a cualquier sensibilidad autonómica, se trata de una autoridad administrativa independiente vinculada al Estado y que no brinda canales de participación a las CCAA $^{101}$.

En el marco de las propuestas para reformar la UEM, también destacan las nuevas normas sobre reformas estructurales ${ }^{102}$. Esta iniciativa pretende crear un nuevo mecanismo de apoyo a los Estados Miembros para implementar reformas estructurales que se hayan identificado durante el procedimiento de supervisión del Semestre Europeo. Así, las reformas estructurales se identifican por los propios Estados en sus PNR, la Comisión aprueba las reformas con un acto legislativo de implementación y aprueba una cantidad para ellas que proviene de la denominada Reserva de rendimiento ${ }^{103}$. Esta Reserva se constituye por el seis por ciento de un conjunto de Fondos europeos: el Fondo Europeo de Desarrollo Regional, el Fondo Social Europeo y los Fondos de Cohesión ${ }^{104}$. Las regiones

96 Comunicación de la Comisión al Parlamento Europeo, al Consejo Europeo, al Consejo y al Banco Central Europeo, de 6/12/2017, COM(2017) 822 final.

97 Propuesta de Directiva del Consejo por la que se establecen disposiciones para reforzar la responsabilidad fiscal y la orientación presupuestaria a medio plazo en los Estados Miembros, de 6/12/2017, $\operatorname{COM}(2017) 824$ final.

98 Propuesta de Directiva del Consejo, $\operatorname{COM}(2017) 824$ final, considerando quinto.

99 Ibid. Art.3.4.

100 Ibid. Art. 3.7.

101 Véase supra nota 74.

102 Propuesta de Reglamento del Parlamento Europeo y del Consejo por el que se modifica el Reglamento (UE) n. ${ }^{\circ} 1303 / 2013$ del Parlamento Europeo y del Consejo, de 17/12/2013, y se deroga el Reglamento (CE) n. ${ }^{\circ} 1083 / 2006$ del Consejo, de 6/12/de 2017, COM(2017) 826 final.

103 Ibid. Art. 1.7.

104 Ibid. Art. 1.5. 
europeas se han opuesto con vehemencia a esta propuesta porque se estaría desviando parte de la Reserva de rendimiento para acometer una finalidad -implementar reformas estructurales - que se desviaría del objetivo de alguno de estos Fondos, entre ellos el de reducir las diferencias regionales en la Unión ${ }^{105}$. Esta propuesta agudiza y visualiza la poca participación de las regiones en la UEM, que ven como parte de los fondos que responden a una lógica regional pasan a formar parte de la estructura de la UEM y, por tanto, se escapan de su capacidad de influencia. La propuesta, por tanto, busca dejar parte de la Reserva de rendimiento en manos de la estructura del Semestre Europeo, es decir, de agentes ajenos a las regiones y, en cierto sentido, se «desregionaliza» la Reserva que pasaría a financiar partidas distintas a los intereses estrictamente regionales.

En definitiva, no se aprecia ningún cambio de rumbo en las estructuras de la UEM que posibilite una mayor influencia de las regiones europeas. Sin embargo, la pandemia abre una ventana de posibilidades, sobre todo a nivel interno, para hacer partícipes a las regiones en el reparto de los fondos extraordinarios europeos para hacer frente a la crisis sanitaria y económica derivada de la Covid-19. La aprobación de estos fondos se ha llevado a cabo de manera excepcional y fuera de las estructuras de la $\mathrm{UEM}^{106}$. Precisamente, la pandemia ha exigido salirse de las costuras de la actual UEM —y de la UEM que se pretende reformar- y esto debería ser tenido en cuenta de cara al futuro. Desde el punto de vista de las regiones, la ventana se abre a nivel interno en la manera en cómo cada Estado Miembro va a gestionar esta capacidad extraordinaria de gasto. En este sentido, cabe destacar que el propio Derecho de la Unión Europea llama, aunque de manera poco asertiva, a la participación y consulta de las autoridades regionales y locales en la gestión de los fondos ${ }^{107}$.

En el caso de España, el documento España puede. Plan de Recuperación, Transformación y Resiliencia constituyó la primera guía de implementación de los fondos de recuperación europeos ${ }^{108}$, mientras que la normativa presupuestaria general

105 Resolución del Comité Europeo de las Regiones sobre la modificación del Reglamento que establece las disposiciones comunes para los Fondos EIE con el objetivo de apoyar las reformas estructurales, de 1/02/2018 (2018/C 176/02).

106 Los fondos excepcionales para el «Plan de recuperación para Europa» se aprobaron mediante acuerdo intergubernamental entre los Estados Miembros el 10 de noviembre de 2020. Este se ha materializado, principalmente, en la aprobación del marco financiero plurianual 2021-2027 (Reglamento (UE, EURATOM) 2020/2093, de 17 de diciembre de 2020) y en el Reglamento (UE) 2021/241 del Parlamento Europeo y del Consejo de 12 de febrero de 2021 por el que se establece el Mecanismo de Recuperación y Resiliencia.

107 Considerando n. 34 Reglamento (UE) 2021/241. Véase JiménEz AsEnsio, R. «El Reglamento (UE) del Mecanismo de Recuperación y Resiliencia: 7 líneas-fuerza y una apostilla», La mirada institucional [consulta: 22 diciembre 2020]. Disponible en: https://rafaeljimenezasensio.com/2021/02/15/el-reglamentoue-de-recuperacion-y-resiliencia-7-lineas-fuerza-y-una-apostilla/.

108 Este documento fue presentado el 7 de octubre de 2020 por el Gobierno español. La Moncloa [consulta: 22 diciembre 2020]. Disponible en: https://www.lamoncloa.gob.es/presidente/actividades/Paginas/2020/espana-puede.aspx. En abril de 2021 este documento será sustituido por un nuevo Plan que será aprobado después de su negociación con la Comisión Europea. 
para 2021 ha empezado a concretar algunas cuestiones acerca de su implementación ${ }^{109}$. Así, el NextGenerationEU otorga a España un total de 140.000 millones de euros, de los cuales 71.000 millones corresponden a transferencias directas, el resto se articula en forma de préstamos ${ }^{110}$. En cuanto a las transferencias directas, 59.168 millones se vehiculan a través del Recovery and Resilience Facility (Mecanismo para la Recuperación y Resiliencia) y a nivel interno no se prevé la participación explícita de las CCAA en su reparto ${ }^{111}$. Por el contrario, los 12.400 millones en transferencias directas previstas en el REACT-EU sí que se explicita que se contará con las CCAA. Más concretamente, en el marco de la política de cohesión de estos fondos, se programarán en colaboración y a través de las CCAA ${ }^{112}$.

La cuestión, por tanto, es cómo se articulará en la práctica esta participación de las CCAA. Véase que la intención del Gobierno español es apartarlas de la gestión de la gran cantidad de los fondos de recuperación europeos, puesto que solamente serán tenidas en cuenta en la gestión de una parte pequeña de aquellos. Asimismo, solamente se hace una referencia somera, sin más detalle, a la Conferencia Sectorial de Fondos Europeos y a la Conferencia de Presidentes Autonómicos, como los mecanismos que permitirán la participación en la gestión de esa parte de los fondos a las CCAA ${ }^{113}$. Todo apunta que la voluntad del Gobierno español es centralizar la gestión de estos fondos y se dejarán pocos canales de cogestión a las CCAA. Esto supone, de nuevo, que se disminuya la capacidad de gasto autonómico, que tendrá poco que decir en qué áreas, sectores o programas podrá ir dirigido el gasto.

La implementación de los fondos extraordinarios europeos para el 2021 se ha llevado a cabo en la línea apuntada. Los Presupuestos Generales del Estado para 2021 incorporan 24.196 millones del Mecanismo para la Recuperación y Resiliencia y 2.436 millones del $R E A C T-E U^{114}$. De nuevo se prevé la participación expresa de las CCAA —en forma de su ejecución, pero no tanto en cuanto a la decisión sobre su destino- en los fondos provenientes del REACT-EU que, en el ejercicio presupuestario del 2021, se prevé dedicarlos a la compra de vacunas contra la Covid-19 y a un plan de renovación de la administración sanitaria para hacer frente a las crisis epidemiológicas ${ }^{115}$. Respecto a los fondos del Mecanismo

109 Véase la Ley 11/2020, de 30 de diciembre, de Presupuestos Generales del Estado para el año 2021. Véase también el Informe económico y financiero de los Presupuestos Generales del Estado para 2021 [consulta: 18 enero 2021]. Disponible en: https://www.sepg.pap.hacienda.gob.es/Presup/PGE2021Proyecto/MaestroTomos/PGE-ROM/doc/L_21_A_A1.PDF.

110 España Puede. Plan de Recuperación, Transformación y Resiliencia, op. cit., pp. 13-14. Véase también el Informe económico y financiero de los Presupuestos Generales del Estado para 2021, op. cit., pp. 95-97.

111 España Puede. Plan de Recuperación. Transformación y Resiliencia, op. cit., p. 13.

112 Ibid. p. 14.

113 Ibid. pp. 18-19.

114 Informe económico y financiero de los Presupuestos Generales del Estado para 2021, op. cit., p. 98.

$115 \mathrm{Ibid}$. El resto de los fondos del REACT-EU previstos para España (8.000 millones) serán destinados directamente a las Comunidades Autónomas durante el 2021 después de la negociación con la Comisión Europea, pero dicha negociación estará en manos del Gobierno. 
para la Recuperación y Resiliencia, serán gestionados en 2021 por las CCAA un total de 10.793 millones, de los cuales 4.243 millones ya están preasignados en los Presupuestos Generales del Estado ${ }^{116}$. De esta manera, solamente 6.540 millones del Mecanismo para la Recuperación y Resiliencia previstos para 2021 y destinados a las CCAA quedan libres de preasignación y, por tanto, estas pueden tener capacidad de decisión.

La capacidad de decisión de las CCAA sobre estos fondos, sin embargo, no se ve reflejado en el nuevo entramado institucional creado al efecto ${ }^{117}$. En líneas generales, parece que efectivamente se centraliza mayoritariamente la gestión y reparto de los fondos y se deja poco espacio a las CCAA $^{118}$. Los mecanismos de gobernanza que se prevén son mayoritariamente de carácter central ${ }^{119}$. Así, se acude al sistema de conferencias sectoriales para hacer partícipes a las CCAA, creando la denominada Conferencia Sectorial del Plan de Recuperación, Transformación y Resiliencia ${ }^{120}$. Está por ver la operatividad práctica de esta conferencia sectorial y realmente el grado de participación efectiva de las CCAA en el reparto y gestión posterior de los fondos. Aunque todo apunta que en aquellos fondos no preasignados $-\mathrm{y}$ no son tantos como se ha visto, puesto que los Presupuestos Generales ya orientan el gasto de una parte significativa de los fondoslos mecanismos de decisión mayoritariamente de carácter central tampoco permitirán un grado de participación elevado de las CCAA.

Esta última y reciente etapa, por tanto, brinda posibilidades para incluir en la cogobernanza del gasto a las CCAA y reducir el impacto de la limitación progresiva de su autonomía financiera. Tanto en la primera etapa (precrisis) como en la segunda (crisis financiera de 2008), la UEM se ha centrado en el control del gasto y la disciplina fiscal de los Estados Miembros, ya sea primero para crear una moneda única como para, en segundo lugar, luchar contra una crisis financiera. Sobre todo, en la segunda etapa, esto ha comportado en el caso de España una fuerte presión que ha llevado a reducir la autonomía financiera de las CCAA. Sin embargo, en la situación de crisis de la pandemia, la reforma de la UEM se ha paralizado y parece que la necesidad de gasto público brinda posibilidades a

116 Informe económico y financiero de los Presupuestos Generales del Estado para 2021, op. cit., pp. 105-108.

117 Real Decreto-ley 36/2020, de 30 de diciembre, por el que se aprueban medidas urgentes para la modernización de la Administración Pública y para la ejecución del Plan de Recuperación, Transformación y Resiliencia.

118 JimÉnEZ AsEnsio, R. «Fondos europeos: entre política y gestión», La mirada institucional [consulta: 22 diciembre 2020]. https://rafaeljimenezasensio.com/2020/12/16/fondos-europeos-entre-politica-y-gestion/.

119 La Comisión para la Recuperación, Transformación y Resiliencia está formada por miembros del ejecutivo central (artículo 14 Real Decreto-ley 36/2020), mientras que el Comité Técnico que le dará apoyo será nombrado por la Comisión (artículo 15 Decreto-ley). El seguimiento de todo el modelo estará en manos del Departamento de Asuntos Económicos y G20 de la Presidencia del Gobierno (artículo 16 Real Decreto-ley 36/2020). Se prevé también la posibilidad de crear foros de participación y grupos de alto nivel, todos ellos disciplinados por el Departamento de Asuntos Económicos y G20 (artículo 17 Real Decreto-ley 36/2020).

120 Artículo 19 Real Decreto-ley 36/2020. 
mecanismos de financiación extraordinarios que, a diferencia de los anteriores periodos, dejan atrás el control férreo del gasto. En la gestión de estos nuevos mecanismos que se articulan fuera de las estructuras de la UEM, sobre todo en el supuesto de los fondos de recuperación europeos, los Estados Miembros pueden ser más sensibles a su propio modelo de organización territorial y facilitar la participación de los entes subestatales. Todavía es pronto para ver cómo evoluciona esta nueva etapa y cómo España gestiona e incorpora los intereses autonómicos en la gestión de los fondos europeos de recuperación de la pandemia.

\section{CONCLUSIONES}

Los grandes choques entre constitucionalismo y proceso de integración europea constituyen solamente una parte de la historia común europea. Otro fenómeno también muy relevante tiene que ver con la transformación, en muchos casos silenciosa e incluso sin sobresaltos, del derecho constitucional nacional bajo la influencia del Derecho de la Unión. Se trata de un fenómeno trascendente, que debe visualizarse y entenderse, puesto que cualquier cambio en las estructuras constitucionales supone la alteración de principios, valores o instituciones que se encuentran enraizados en el sistema político de un Estado Miembro. Poner luz y taquígrafo a las transformaciones constitucionales derivadas del proceso de integración europea conlleva entender mejor la relación entre un Estado Miembro y su encaje en el proyecto común europeo, facilita la implementación de los objetivos de la Unión a nivel interno, permite identificar dificultades y, en definitiva, clarifica una integración, la europea, que no está exenta en muchas ocasiones de opacidad en cuanto a sus principios relacionales con los Estados embarcados en ella.

El Estado autonómico es, precisamente, una de las estructuras constitucionales relevantes en la Constitución española de 1978. Forma parte de las decisiones originarias del constituyente que erigió un modelo de descentralización territorial garantizado constitucionalmente, pero, a su vez, de carácter indeterminado y abierto a su concreción posterior. Esta doble característica del modelo de organización territorial español - garantizado constitucionalmente en sus valores y principios, pero abierto en cuanto a su concreción - lo ha dotado de una especial sensibilidad ante el proceso de integración europea. Asimismo, sus características únicas lo convierten en un caso relevante para testar, lejos de los grandes choques con el constitucionalismo nacional, la capacidad de transformación y permeabilidad de la integración europea en el derecho constitucional interno.

En efecto, la influencia de la UEM en el Estado autonómico es indudable y puede afirmarse que se ha producido, desde los años noventa, una progresiva reducción de la autonomía financiera de las CCAA. Si bien el objetivo de la UEM ha sido disciplinar el gasto de los Estados Miembros y mantener a raya los niveles de déficit y deuda públicos, sin maniatar teóricamente a los Estados Miembros en 
los medios utilizados para alcanzar tales objetivos, en la práctica España se ha visto obligada a revisar el Estado autonómico. En la UEM precrisis, momento en el que se fijaron los principios sustantivos de estabilidad presupuestaria y el control del déficit y deuda públicos, no se ató en corto a los Estados Miembros desde la Unión y esto comportó un marco normativo español que todavía dejaba cierto margen de actuación a las CCAA. En la UEM en crisis, sin embargo, la situación cambió radicalmente y la presión desde las estructuras de supervisión de la UEM comportó un golpe de timón a nivel interno español que redujo significativamente la capacidad de gasto de las CCAA. En el contexto actual de lucha contra la pandemia, se abren posibilidades a una mayor participación de las CCAA en el gasto de los fondos europeos de recuperación, pero no se entrevén modificaciones de calado en las estructuras de la UEM.

En esta progresiva transformación del Estado autonómico adquirió una gran relevancia el diálogo entre España y las instituciones de la Unión en el marco de los sistemas de supervisión de la UEM. Se ha detallado una comunicación intensa entre el Gobierno español y las instituciones de la Unión durante la crisis financiera de 2008 en la que las CCAA fueron señaladas como agentes incumplidores y se alentó a España a atajar el déficit regional y a aplicar con rigor el régimen de estabilidad presupuestaria. En este diálogo la Unión no se mostró como neutral en cuanto a los medios utilizados por España para reducir su déficit y deuda públicos excesivos o sus desequilibrios macroeconómicos, al contrario, las instituciones de la Unión señalaron los responsables del incumplimiento y urgieron a tomar medidas al efecto. En definitiva, la reforma del marco constitucional y legislativo de estabilidad presupuestaria, que comportó límites sustantivos a la autonomía financiera de las CCAA y por primera vez un marco preventivo y sancionador en caso de incumplimiento, aconteció en el contexto de este diálogo entre España y las instituciones de la Unión.

Todo ello sin que las CCAA tuvieran capacidad de participación en los procesos de toma de decisiones, tanto a nivel de la Unión como a nivel estatal. La UEM no ha sido diseñada para dar voz a las regiones europeas y todo se fía a los mecanismos internos estatales de participación a disposición de las regiones. En el caso de España, la participación de las CCAA en la determinación de la posición del Estado ante la Unión ha presentado desde sus inicios serias deficiencias. Y en el caso de la normativa de estabilidad presupuestaria, su primera formulación dejaba espacio a las CCAA en la fijación individualizada del déficit público para después ya centralizar mucho más el control del gasto y reducir la participación de aquellas en su determinación y gestión.

Esta transformación del Estado autonómico no ha sido el objetivo de la UEM, centrada en garantizar la disciplina fiscal de los Estados Miembros, pero sí que aparece como un resultado en el que ha influido decisivamente. Sobre todo, en el diálogo que ha acontecido en la UEM en crisis, la Unión fue más allá de señalar objetivos y situó a las CCAA en el epicentro de la tarea de reducir el déficit público de España. El endurecimiento de la normativa española de estabilidad 
presupuestaria, en claro detrimento de la autonomía financiera de las CCAA, recibió un claro apoyo desde las estructuras de la UEM.

En todo caso, esta transformación se ha vivido con naturalidad por parte del Tribunal Constitucional. La desconstitucionalización del modelo de organización territorial y su indeterminación han posibilitado la interiorización del cambio y la reducción de la autonomía financiera de las CCAA ha sido asumida en la jurisprudencia constitucional sin sobresaltos. La transformación del Estado autonómico se erige como un ejemplo de choque de baja intensidad entre el constitucionalismo español y el proceso de integración europea. La Unión demandaba a España una mayor disciplina de gasto y control del déficit y deuda públicos, esta a su vez ha centrado el esfuerzo en disciplinar fiscalmente a las CCAA. En esta tarea común, tanto la Unión como el Gobierno central no han encontrado en la protección constitucional del Estado autonómico una barrera sólida que les impidiera la consecución de sus objetivos.

TITLE: The Economic and Monetary Union and Autonomous Communities: the transformation of the principle of financial autonomy

ABstract: A distinctive feature of the State of Autonomies is the recognition of political autonomy of the Autonomous Communities and, inherent to it and at the same time a necessary instrument to make it possible, the financial autonomy. The Spanish constitutional system provides protection to that autonomy, both at the textual and case-law levels. The Economic and Monetary Union (EMU), however, has led a substantial transformation of the financial autonomy as a constitutional value, from the perspective of the spending power, of the Autonomous Communities. This article explores this transformation and identifies three stages -EMU precrisis, EMU in crisis and the current efforts of reforming the EMU and the allocation and management of the European funds for recovery — which have shaped the financial autonomy of the Autonomous Communities. The article analyzes the interaction between the Spanish constitutional system and the European Union Law and points out the latter as an engine of a constitutional transformation and as a decisive factor in the evolution of the State of Autonomies.

ReSUMEN: Un rasgo distintivo del Estado de las Autonomías es el reconocimiento de la autonomía política de las CCAA y, consustancial a ella y a la vez instrumento necesario para hacerla posible sobre todo en su vertiente de la potestad de gasto, también la autonomía financiera. El ordenamiento constitucional espanol ha amparado esta autonomía, tanto a nivel textual como a través del moldeamiento del Tribunal Constitucional. Sin embargo, la Unión Económica y Monetaria (UEM) ha comportado una transformación sustancial de la perspectiva constitucional de la autonomía financiera, en su vertiente de la potestad de gasto, de las CCAA. Este artículo explora esta transformación, identificando tres etapas distintas - UEM precrisis, UEM en crisis y los intentos actuales de reforma de la UEM y la gestión de los fondos europeos de rescate - que han ido moldeando el principio constitucional de autonomía financiera de las CCAA. Se analiza la interacción entre el ordenamiento constitucional español y el Derecho de la Unión y se señala a este último como motor de transformación constitucional y como un factor decisivo en cuanto a la evolución de la organización territorial del estado español.

KEY WORDS: State of Autonomies, financial autonomy, Economic and Monetary Union (EMU).

Palabras Clave: Estado autonómico, autonomía financiera, Unión Económica y Monetaria (UEM).

FECHA DE RECEPCIÓN: 30.12.2020

FECHA DE ACEPTACIÓN: 26.01.2021

UNED. Teoría y Realidad Constitucional, núm. 47, 2021, ISSN 1139-5583, pp. 383-408 